\title{
Expression of neuronal nitric oxide synthase in the developing superficial layers of the rat superior colliculus
}

A. Giraldi-Guimarães,

R.E. Bittencourt-Navarrete and R. Mendez-Otero

\section{Correspondence}

R.M. Otero

Instituto de Biofísica

Carlos Chagas Filho, CCS, Bloco G

21941-590 Rio de Janeiro, RJ

Brasil

Fax: +55-21-2280-8193

E-mail: rmotero@biof.urrj.br

Research supported by CNPq, PRONEX, and FAPERJ to R. MendezOtero and a grant from the MCT to the Millennium Institute for Tissue Bioengineering, Brazil.

Received June 24, 2003

Accepted February 18, 2004

....................

\author{
Laboratório de Neurobiologia Celular e Molecular, \\ Instituto de Biofísica Carlos Chagas Filho, \\ Universidade Federal do Rio de Janeiro, \\ Rio de Janeiro, RJ, Brasil
}

\begin{abstract}
We investigated the level of expression of neuronal nitric oxide synthase (nNOS) in the retinorecipient layers of the rat superior colliculus during early postnatal development. Male and female Lister rats ranging in age between the day of birth $(\mathrm{P} 0)$ and the fourth postnatal week were used in the present study. Two biochemical methods were used, i.e., in vitro measurement of NOS specific activity by the conversion of $\left[{ }^{3} \mathrm{H}\right]$-arginine to $\left[{ }^{3} \mathrm{H}\right]$-citrulline, and analysis of Western blotting immunoreactive bands from superior colliculus homogenates. As revealed by Western blotting, very weak immunoreactive bands were observed as early as P0-2, and their intensity increased progressively at least until P21. The analysis of specific activity of NOS showed similar results. There was a progressive increase in enzymatic activity until near the end of the second postnatal week, and a nonsignificant tendency to an increase until the end of the third week was also observed. Thus, these results indicated an increase in the amount of nNOS during the first weeks after birth. Our results confirm and extend previous reports using histochemistry for NADPH-diaphorase and immunocytochemistry for nNOS, which showed a progressive increase in the number of stained cells in the superficial layers during the first two postnatal weeks, reaching an adult pattern at the end of the third week. Furthermore, our results suggested that nNOS is present in an active form in the rat superior colliculus during the period of refinement of the retinocollicular pathway.
\end{abstract}

\section{Introduction}

Nitric oxide (NO) is a membrane-permeable gas that was first identified as endothelium-derived relaxing factor (1). However, it is also synthesized in the nervous system and functions as an important intercellular messenger in neurotransmission, excitotoxicity, plasticity, and control of cerebral blood flow (2-4). The enzyme responsible for NO syn-
Key words

- Superior colliculus

- Nitric oxide synthase

- Development

- Retinotectal projection 
regions (7-12). nNOS was first described as a constitutively expressed protein; however, recent studies have shown that nNOS expression levels change in response to a variety of physiological and pathological stimuli (13).

The study of NOS expression during the development of the retinotectal pathway is relevant in view of some evidence indicating a role for NO in the formation of the topographic map in this system. For example, in chickens, the elimination of the ipsilateral retinotectal projections is partially dependent on the NO synthesized in the tectum opticum (14). Furthermore, several studies on rodents have suggested that NO might be involved in the topographic establishment of the ipsilateral retinotectal projections (15-18).

The presence of NOS-positive cells in the retinorecipient superficial layers of the superior colliculus has been reported in several mammalian species (19-25). In the rat, a subpopulation of all the different cell types described in the superficial layers of the superior colliculus by the Golgi technique (26) expresses nNOS $(21,27,28)$. Previous studies have also shown that the first NOSpositive cells in these layers appear by the end of the first postnatal week (between the fifth and the seventh postnatal day). Their numbers increase over the following days, reaching an adult pattern of NOS expression at the end of the third week $(19,20)$.

All of these previous studies dealt with qualitative aspects of the expression of nNOS in the superior colliculus. In the present study, we have investigated nNOS expression and activity during the postnatal development of the superficial layers of the rat superior colliculus by means of quantitative biochemical analysis and Western blotting.

\section{Material and Methods}

\section{Animals}

We used male and female Lister rats ranging in age between the day of birth (P0) and the fourth postnatal week. The animals were housed in our colony in a room with controlled temperature and maintained on a 12:12-h light/dark cycle with food and water available ad libitum. All experimental protocols were approved by the Committee for the Use of Experimental Animals of our institution and followed NIH guidelines.

\section{Chemicals}

$\mathrm{L}-2,3,4,5-\left[{ }^{3} \mathrm{H}\right]$-arginine monohydrochloride was obtained from Amersham (São Paulo, SP, Brazil). The ion-exchange resin DOWEX AG50W-X8 $\left(\mathrm{Na}^{+}\right.$form) was obtained from Bio-Rad (Hercules, CA, USA). The enhanced chemiluminescence Western blotting system was obtained from Amersham Pharmacia Biotech (São Paulo, SP, Brazil), including a secondary antibody conjugated with horseradish peroxidase (HRP). All other reagents and chemicals were purchased from Sigma (St. Louis, MO, USA).

\section{Antibodies}

Two anti-nNOS antibodies were used: a monoclonal (mouse) anti-nNOS (Sigma), which was prepared against a fragment (amino acids 1-181) of the N-terminal region of nNOS from the rat brain (29); a polyclonal (rabbit) anti-nNOS (Transduction Laboratories, Lexington, KY, USA), which was prepared against the $\mathrm{C}$-terminal region of nNOS (amino acids 1095-1289). The monoclonal antibody recognizes only the $\mathrm{nNOS} \alpha$ isoform and the polyclonal antibody recognizes the $\alpha, \beta$ and $\gamma$ isoforms.

Tissue preparation for biochemical analysis

Animals ranging from $\mathrm{P} 0$ to $\mathrm{P} 23$ were decapitated under deep anesthesia with sodium pentobarbital $(50 \mathrm{mg} / \mathrm{kg}$, ip $)$ and the brains were removed from the skull. The 
upper layers of the superior colliculus were carefully dissected and washed with cold $0.9 \% \mathrm{NaCl}$. They were then weighed and homogenized at $4^{\circ} \mathrm{C}$ in five volumes (w/v) of $50 \mathrm{mM}$ Tris buffer, $\mathrm{pH}$ 7.0, containing 320 $\mathrm{mM}$ sucrose, $1 \mathrm{mM}$ ethylenediaminetetraacetic acid (EDTA), $1 \mathrm{mM}$ dithiothreitol (DTT), $10 \mu \mathrm{g} / \mathrm{ml}$ leupeptin, $10 \mu \mathrm{g} / \mathrm{ml}$ soybean trypsin inhibitor, and $2 \mu \mathrm{g} / \mathrm{ml}$ aprotinin. For both the enzymatic activity measurements and the electrophoretic procedure, each homogenate consisted of the tissue dissected from a single animal, corresponding to an experimental sample. The homogenates were then centrifuged at $10,000 \mathrm{~g}$ for $20 \mathrm{~min}$ at $4^{\circ} \mathrm{C}$ to mainly remove the blood vessels and nuclear material. Only the supernatants were used in the assays.

\section{NOS activity}

NOS activity was determined by measuring the formation of L-citrulline from Larginine (30). Briefly, 10-20 $\mu$ of each sample was added to Eppendorf microtubes with 50 $\mu 1$ of $50 \mathrm{mM}$ potassium phosphate buffer, $\mathrm{pH} 7.2$, containing $1.2 \mathrm{mM} \mathrm{MCl}_{2}, 0.25 \mathrm{mM}$ $\mathrm{CaCl}_{2}, 60 \mathrm{mM}$ L-valine, $1.2 \mathrm{mM}$ L-citrulline, $25 \mu \mathrm{M}$ L-arginine, $1 \mathrm{mM}$ DTT, $4 \mu \mathrm{M}$ flavin adenine dinucleotide, $4 \mu \mathrm{M}$ flavin mononucleotide, $120 \mu \mathrm{MNADPH}$, and $\left[{ }^{3} \mathrm{H}\right]-$ L-arginine $(1 \mathrm{mCi} / \mathrm{ml}, 59 \mathrm{Ci} / \mathrm{mmol})$. After incubation for $30-45 \mathrm{~min}$ at $25^{\circ} \mathrm{C}$, the reaction was stopped by the addition of $500 \mu 1$ Dowex resin AG-50WX8 (200-800, $\mathrm{Na}^{+}$ form) (1:1 in water). The microtubes were then centrifuged at 2,000 $g$ for $5 \mathrm{~min}$ to pellet the resin and an aliquot of the supernatants was removed to measure the emission of $\beta$ radiation from $\left[{ }^{3} \mathrm{H}\right]$-L-citrulline by liquidscintillation counting. A $10-20-\mu 1$ aliquot of the same sample was added to microtubes containing 1 mM EGTA (to detect the $\mathrm{Ca}^{2+}$ independent NOS activity) or $1 \mathrm{mM}$ EGTA plus $1 \mathrm{mM} \mathrm{N}{ }^{\omega}$-nitro-L-arginine (to provide a negative control for counting). These preparations were used to obtain the blank values and no difference between the two blank microtubes was found. The final counting value of each sample was the number of counts less the counts of the blank microtube. Each sample and its respective blank were prepared in duplicate, and the mean was used for the calculations. The protein concentration of the samples was determined by the technique of Bradford (31) and the enzymatic activity was reported as picomol of citrulline per $\mathrm{mg}$ of total protein per min for each sample.

Data were analyzed statistically by ANOVA and by the Tukey multiple comparison post-test.

\section{Electrophoresis (SDS-PAGE) and Western blotting}

An aliquot containing $30 \mu \mathrm{g}$ protein (for immunoblotting using the monoclonal antibody) or $65 \mu \mathrm{g}$ protein (for immunoblotting using the polyclonal antibody) from each sample was mixed with electrophoresis sample buffer containing $50 \mathrm{mM}$ Tris- $\mathrm{HCl}$, $2 \%(\mathrm{w} / \mathrm{v})$ sodium dodecyl sulphate (SDS), $5 \%$ (v/v) B-mercaptoethanol, $\mathrm{pH}$ 6.8, and $10 \%$ glycerol $(\mathrm{v} / \mathrm{v})$. Samples were boiled for 5 min prior to loading onto $10 \%$ SDSpolyacrylamide gel for electrophoresis using the Mini-Protean 3 electrophoresis module (BioRad). After separation on the gel, the proteins were transferred to a nitrocellulose membrane $(0.45-\mu \mathrm{m}$ pore $)$ and submitted to the following sequential incubations: $5 \%$ milk in $10 \mathrm{mM}$ phosphate-buffered saline (PBS) for $1 \mathrm{~h}$, monoclonal (1:2000) or polyclonal $(1: 1000)$ anti-nNOS antibodies diluted in the previous solution overnight followed by the secondary antibody (goat anti-mouse or goat anti-rabbit) conjugated to HRP and diluted 1:5000 in $10 \mathrm{mM}$ PBS and $0.1 \%$ nonidet $\mathrm{P}-40$ for $2 \mathrm{~h}$. After several additional washes in PBS, immunoreactive bands were visualized on a film impregnated with an enhanced chemiluminescence kit. 
Histochemistry and immunohistochemistry

Animals were anesthetized with an overdose of sodium pentobarbital $(50 \mathrm{mg} / \mathrm{kg}$, ip) and perfused intracardially with cold $0.9 \%$ $\mathrm{NaCl}$ followed by $4 \%$ paraformaldehyde (PF) or $2 \%$ glutaraldehyde (GLUT) $+0.5 \% \mathrm{PF}$ in $100 \mathrm{mM}$ phosphate buffer, pH 7.4 (29). Brains were removed and immersed in 100 $\mathrm{mM}$ phosphate buffer containing $20 \%$ sucrose for $24 \mathrm{~h}$ at $4^{\circ} \mathrm{C}$. After this period, the midbrain was cut into $30-60-\mu \mathrm{m}$ sections at $-20^{\circ} \mathrm{C}$ with a CM 1850 cryostat (Leica Instruments GmbH, Heidelberg, BadenWurttemberg, Germany). For NADPH-diaphorase (NADPH-d) histochemistry, the brain sections from animals perfused with one or the other fixative solution were washed twice in $50 \mathrm{mM}$ Tris- $\mathrm{HCl}$ buffer, $\mathrm{pH} 7.4$, and reacted as free-floating sections at $37^{\circ} \mathrm{C}$ for at least $1 \mathrm{~h}$. The reaction solution contained $1 \mathrm{mM} \beta$ NADPH (reduced form), $0.5 \mathrm{mM}$ nitroblue tetrazolium dissolved in dimethylsulfoxide (DMSO, at a final concentration of 1:1000 DMSO:buffer, v/v) and 1\% Triton X-100 in $50 \mathrm{mM}$ Tris- $\mathrm{HCl}$ buffer, $\mathrm{pH}$ 7.4. As a control, some sections were incubated without $\beta$ NADPH, with no staining being observed.

For immunohistochemistry, brain sections from animals perfused with 4\% PF were washed twice in PBS (100 mM phosphate buffer, $\mathrm{pH} 7.4$, and $0.9 \%$ sodium chloride) and then preincubated as free-floating sections in PBS $+0.3 \%$ Triton X-100 with $10 \%$ normal goat serum for $60 \mathrm{~min}$ at room temperature. They were then incubated in the same solution supplemented with the monoclonal anti-nNOS antibody (1:400) for $24 \mathrm{~h}$. Bound primary antibody was visualized by means of a Cy3-conjugated goat anti-mouse antibody (Jackson; 1:1000) incubated for 2 h. Control sections prepared without incubation with the primary antibody did not show any staining.

Sections reacted for NADPH-d were examined under light field illumination and those reacted for immunohistochemistry were analyzed under fluorescent illumination, using a Zeiss microscope in both cases. Images were obtained with an AxioCam digital camera connected to the microscope and the Zeiss Axiovision 3.0 software.

\section{Results}

We used the immunoblot and enzyme activity to demonstrate the presence of nNOS in the tissue homogenate obtained from the developing rat superior colliculus to complete the histochemical data $(19,20)$. There was a progressive increase in the amount of the enzyme during the first three weeks after birth. Figure 1A shows a representative immunoblotting using a specific monoclonal antibody to the nNOS $\alpha$ isoform (estimated molecular mass: $160 \mathrm{kDa}$ ). A very weak immunoreactive band was observed as early as $\mathrm{P} 0-2$, with its intensity increasing progressively at least until P21, the last age studied in the present investigation. Interestingly, when using a polyclonal antibody that recognizes all the isoforms of nNOS, a second band was observed in addition to the $\mathrm{nNOS} \alpha$ isoform band. This second band was slightly lighter than the first and corresponded to the nNOSB isoform with a molecular mass near $135 \mathrm{kDa}$ (Figure 1B) (32). Although the intensity of this second band varied, it seemed to increases progressively, as observed for the nNOS $\alpha$ isoform band (Figure 1B). These results indicate that both isoforms follow the same pattern of expression during development of the superior colliculus.

In addition to the identification of the presence of nNOS during postnatal development, it was important to determine whether the increase in the amount of protein actually corresponded to an increase in catalytic activity. In order to confirm its identification and determine the specific activity of nNOS during this period we used a radioenzymatic assay to measure the conversion of L-arginine to L-citrulline in the superior colliculus homogenates. Figure 1C shows the enzy- 
matic activity of nNOS from the first postnatal days (P0-2) to the third week after birth (P20-23). There was a progressive increase in enzymatic activity until near the end of the second postnatal week, followed by a nonsignificant tendency to an increase until the end of the third week (Figure 1C). Thus, the results of both the immunoblotting and the catalytic activity measurements indicated an increase in the amount of the nNOS during the first weeks after birth. However, the level of activity seemed to reach a peak first, despite a subsequent increase in the protein level (Figure 1A). Part of the enzymatic ac-

Figure 1. Demonstration of neuronal nitric oxide synthase (nNOS) in rat superior colliculus homogenates by immunoblot and enzymatic activity. $A$, Western blot analysis of nNOS in extracts from the upper layers of the rat superior colliculus obtained at postnatal $(P)$ ages (in days) P1, P5, P9, P15 and P21. Equal amounts of protein were loaded onto each well. The bands which were immunoreactive with monoclonal anti-nNOS $\alpha$ were visualized with a secondary antibody conjugated with horseradish peroxidase. Note a gradual increase in the expression of $\mathrm{nNOS} \alpha(\sim 160 \mathrm{kDa})$ over the first postnatal weeks. The illustrated film is representative of two independent experiments, each using different animals. $B$, Western blot analysis of nNOS in extracts from the upper layers of the rat superior colliculus obtained at P1, P7 and during adulthood using a second anti-nNOS antibody that recognizes all nNOS isoforms. In addition to the nNOS $\alpha$ band, note a second band which corresponds to nNOSß ( 135 kDa). Despite the variability in the intensity of this second band, as illustrated in the lines obtained from the two different adults $\left(A D\right.$ and $\left.A D_{(2)}\right)$ used in this representative experiment, nNOSß expression also seemed to increase during postnatal development. The film presented is representative of two independent experiments, each using different animals. Neuron-specific enolase (NSE, 47 kDa) was used as a "housekeeping" protein to control loading and, as expected, no difference in protein levels was observed. C, NOS activity in extracts from the upper layers of rat superior colliculus, reported as pmol citrulline/mg protein-1 $\mathrm{min}^{-1}$. The enzymatic activity increased from the beginning of the first postnatal week (P0-2) to the end of the third postnatal week (P20-23), in agreement with the immunoblot results. Maximum NOS activity was reached in the course of the third postnatal week. Each bar represents the mean \pm SEM of enzyme activity for each group: P0-2 (N=6), P5-8 $(N=10), P 10-12(N=5), P 14-16(N=7)$, and P20-23 $(N=6)$. ANOVA revealed a significant difference between all groups $(\mathrm{P}<0.001)$. Tukey's multiple comparisons post-test revealed a significant difference between $\mathrm{P} 0-2$ and $\mathrm{P} 10-12\left({ }^{*} \mathrm{P}<0.05\right), \mathrm{P} 0-2$ and $\mathrm{P} 14-16$ (**P $<0.01), \mathrm{P} 0-2$ and P20-23 (**P $<0.01), \mathrm{P} 5-8$ and P14-16 ( $\left.{ }^{*} \mathrm{P}<0.05\right)$, and P5-8 and P20-23 ( $\left.{ }^{*} \mathrm{P}<0.05\right)$. tivity could be due to the endothelial eNOS although most of the blood vessels were removed during the centrifugation procedure. Thus, we checked the possibility that some neurons could express eNOs since the expression of this isoform by neurons has been already described in other regions of the central nervous system (29). eNOS immunohistochemistry revealed no significant staining at P5, indicating that this isoform does not contribute to the catalytic activity of the NOS observed in the superficial layers of the superior colliculus at this age (data not shown).
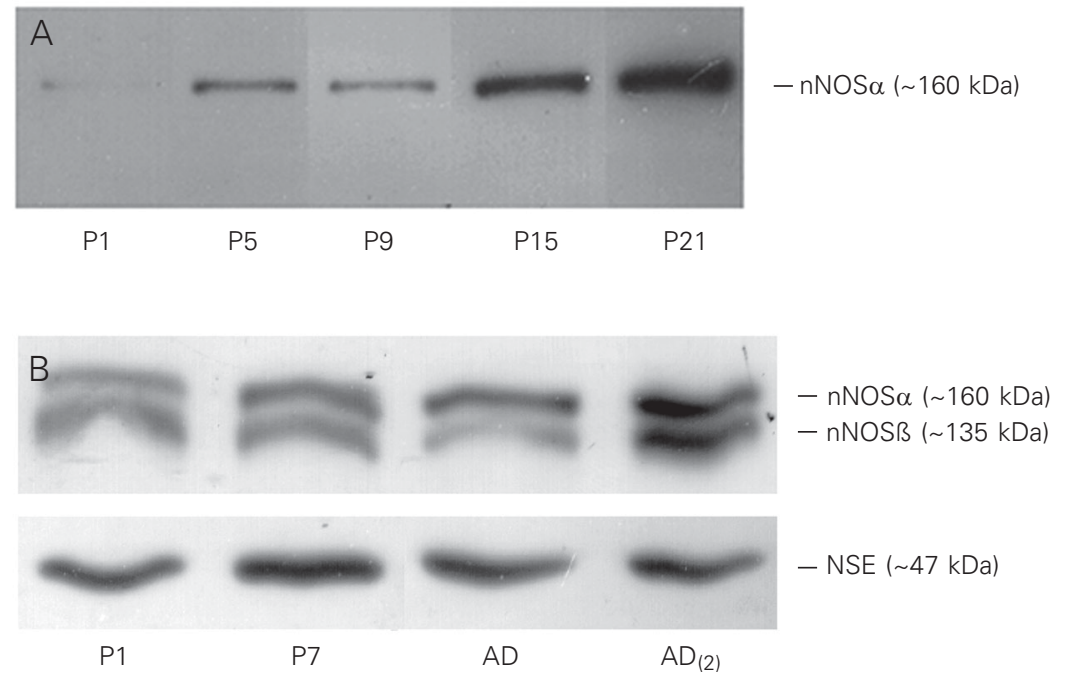

C

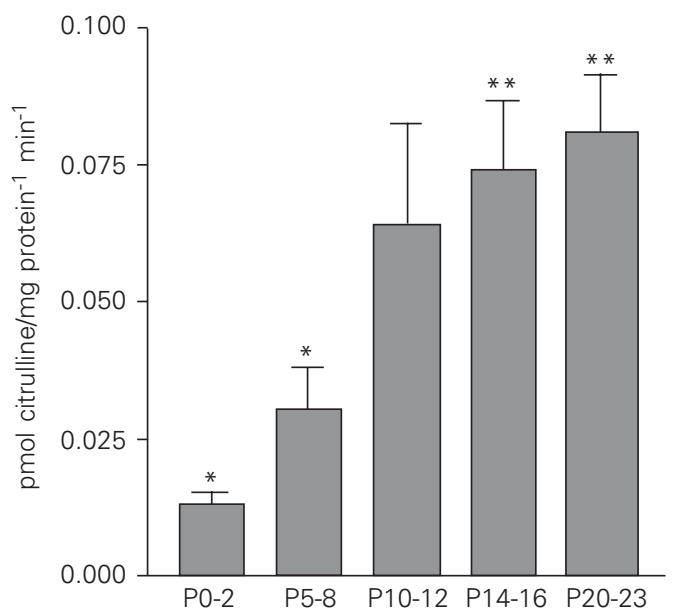


Previous studies using NADPH-d histochemistry in the rat superior colliculus $(19,20)$ have reported the appearance of the first NOS-positive cells only at P7. However, with both the immunoblots and radioenzymatic assays we were able to detect the enzyme and its activity as early as P0 although at very low levels. It is possible that the histochemical and immunohistochemi- cal studies were not sensitive enough to detect these low levels of the enzyme. Alternatively, it is possible that in this region nNOS staining might be highly sensitive to the fixation protocols used, as reported for other regions of the central nervous system $(29,33)$. We then performed NADPH-d staining using different fixative solutions and nNOS immunohistochemistry. NADPH-d histo-
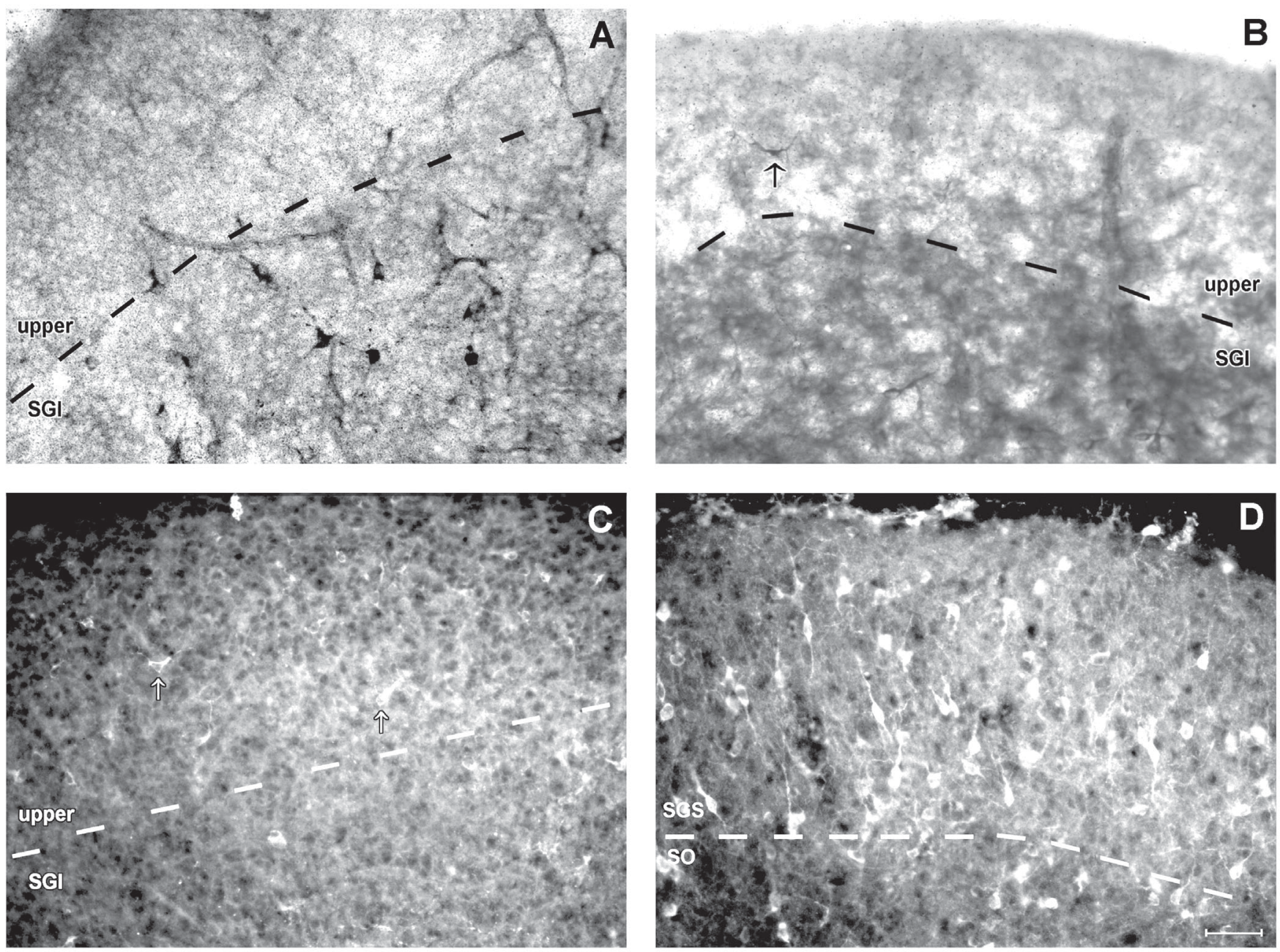

Figure 2. Neuronal nitric oxide synthase (nNOS) histochemistry and immunohistochemistry in the rat superior colliculus. $A, N A D P H-d$ histochemistry at P5 after fixation with $4 \%$ paraformaldehyde (PF). No stained cells were observed in the upper layers, but a few labelled cells were found in the stratum griseum intermediale (SGI). B, NADPH-d histochemistry at P5 after fixation with $2 \%$ glutaraldehyde (GLUT) $+0.5 \%$ PF. Note that this fixation procedure increased the sensitivity of the NADPH-d reaction, with some stained cells (arrow) now being observed at this age, earlier than with $4 \%$ PF. $C, n N O S$ immunohistochemistry at P5. As observed with NADPH-d with GLUT + PF, this technique revealed more stained cells than histochemistry with PF only. The arrows indicate rare stained cells observed in the upper layers of the superior colliculus. $D$, nNOS immunohistochemistry in adult animals. Note that the number of stained cells increased dramatically at this age when compared with that found at P5. These results agree with the measurement of the total amount of nNOS protein during the postnatal development of the upper layers of the superior colliculus. In all micrographs, broken lines represent an approximated boundary between the indicated layers, and the pial surface, when not visible, was always located near the upper border of the figure. Upper $=$ stratum opticum (SO) and stratum griseum superficiale (SGS). Calibration bar $=100 \mu \mathrm{m}$ for all panels. 
chemistry in animals fixed with 4\% PF revealed no stained cells in the upper layers of the superior colliculus at P5 (Figure 2A), confirming previous results $(19,20)$. However, NADPH-d histochemistry in tissue fixed with $2 \%$ GLUT $+0.5 \%$ PF showed stained cells in these layers at this age, although in very small numbers (Figure 2). These results were also confirmed by immunohistochemistry (Figure 2C) which revealed scattered cells in the superior colliculus at P5. Thus, NADPH-d histochemistry after fixation with GLUT or immunohistochemistry was apparently more sensitive than NADPH-d histochemistry after fixation with $4 \% \mathrm{PF}$ in detecting the lower levels of nNOS at P5. However, in adulthood the number of stained cells dramatically increased (Figure 2D), as also reported previously $(19,21,27,28)$.

\section{Discussion}

We have quantitatively analyzed the expression of nNOS in the superficial layers of the rat superior colliculus during the period of postnatal development. In general, our results agree with previous histochemical studies of the expression of this enzyme $(19,20)$ which showed a progressive increase in the number of stained cells in the collicular retinorecipient layers of the superior colliculus during the first two postnatal weeks, reaching an adult pattern of expression at the end of the third week. The total amount of nNOS protein assayed by Western analysis, as well as its catalytic activity measured by the conversion of L-arginine to L-citrulline, also followed a similar pattern during the first postnatal weeks, reaching a maximal amount during the third postnatal week, the last period of postnatal development studied here. We cannot exclude a possible decrease in NOS expression after the third week. Cork et al. (23) observed a decrease after the peak of NOS expression during the postnatal development of the mouse superior colliculus by histochemical labeling. Nevertheless, since our biochemical data correlated well with the previous histochemical descriptions for the rat superior colliculus, we would argue that a decrease after the third week is not likely because the previous studies did not show a decrease in NOS staining at this time $(19,20)$.

Our results differ from those observed by Campello-Costa et al. (16). In their study, using a radioenzymatic assay and a histochemical assessment of NADPH-d activity from homogenates of the superficial layers of the superior colliculus, they showed that the maximal level of nNOS expression was at postnatal day 5 and that there was a decrease in the enzymatic activity during the following weeks reaching a significantly lower level in adulthood. At present, we are not able to explain the discrepancy with our results obtained with immunochemistry and enzyme activity which did not show any peak at P5. In addition, from their results (16), we would expect to find a larger number of NADPH-positive cells at P5 in tissue sections and also in immunohistochemical staining. However, using the most sensitive variations of these techniques we did not find a significant number of labeled cells at P5. Actually, at this age only very few cells are labeled and the number and intensity of staining increases progressively, reaching a peak only during the third postnatal week.

We also were able to conclude that there is no significant expression of eNOS by the collicular cells at the end of the first postnatal week since the use of NAPDH-d with GLUT did not show any significant staining at this age. This last possibility was also assessed by immunohistochemistry for eNOS. Similarly, we did not observe any significant staining at P5 (data not shown), confirming that this isoform did not contribute to the low catalytic activity of NOS observed in the superficial layers of the superior colliculus.

Several lines of evidence suggest that NO synthesis occurs downstream from acti- 
vation of the $N$-methyl-d-aspartate (NMDA) receptor, and it has been suggested that $\mathrm{NO}$ could act as a retrograde messenger in synaptic plasticity, influencing both the refinement and stabilization of co-active afferent terminals and the induction of long-term changes in synaptic potency $(2,34-38)$. Our results showed that during the first two postnatal weeks, the period when the final retinotopic map is established in the rat superior colliculus (39), nNOS is expressed at lower levels than in adulthood. However, the potential amount of NO synthesis by the nNOS present in this period, as assayed indirectly by the levels of enzymatic activity, seems to be sufficient to participate in the formation of this map, since previous studies with NOS inhibitors have shown that the blockage of NO synthesis impairs the refinement of retinocollicular projections $(16,17)$.

Long-term changes in retinocollicular transmission might be involved in the refinement of the retinocollicular projection during the postnatal development of the rat superior colliculus (37). In fact, both long-term depression and long-term potentiation can be induced in the superior colliculus after stimulation of optic tract fibers in an in vitro isolated brainstem preparation during the period of refinement of this pathway (40). In addition, the cited investigators have shown that in the superior colliculus, as in other structures, long-term potentiation is NMDA receptor-dependent (40). Since NO synthesis has also been linked to the NMDA receptor activity, it is possible that the role of $\mathrm{NO}$ in the retinocollicular refinement might be through a mechanism of long-term synaptic strengthening during postnatal development. A role for $\mathrm{NO}$ in the induction of long-term potentiation has been suggested by several investigators $(2,35)$, although this hypothesis is still the subject of some controversy (38). Additional studies are needed to identify the involvement of $\mathrm{NO}$ in the induction of longterm potentiation in the superior colliculus, which would shed light on the functional roles of this molecule in collicular physiology.

\section{Acknowledgments}

We thank Dr. Leny A. Cavalcante (Instituto de Biofísica Carlos Chagas Filho, Universidade Federal do Rio de Janeiro) for helpful comments about the manuscript and Felipe Marins for technical support.

\section{References}

1. Palmer RM, Ferrige AG \& Moncada S (1987). Nitric oxide release accounts for the biological activity of endothelium-derived relaxing factor. Nature, 327: 524-526.

2. Dawson TM \& Snyder SH (1994). Gases as biological messengers: nitric oxide and carbon monoxide in the brain. Journal of Neuroscience, 14: 5147-5159.

3. Schuman EM \& Madison DV (1994). Nitric oxide and synaptic function. Annual Review of Neuroscience, 17: 153-183.

4. Cudeiro J \& Rivadulla C (1999). Sight and insight - on the physiological role of nitric oxide in the visual system. Trends in Neurosciences, 22: 109-116.

5. Bredt DS \& Snyder SH (1992). Nitric oxide, a novel neuronal messenger. Neuron, 8: 3-11.

6. Förstermann U, Schmidt HHHW, Pollock JS, Sheng H, Mitchell JA, Warner TD, Nakane M \& Murad F (1991). Isoforms of nitric oxide synthase: characterization and purification from different cell types. Biochemical Pharmacology, 42: 1849-1857.

7. Mikuzawa K, Vincent SR, McGeer PL \& McGeer EG (1989). Distribution of reduced nicotinamide adenine dinucleotide phosphate dia- phorase-positive cells and fibers in the cat central nervous system. Journal of Comparative Neurology, 279: 281-311.

8. Bredt DS, Glatt CE, Hwang PM, Fotuhi M, Dawson TM \& Snyder SH (1991). Nitric oxide synthase protein and mRNA are discretely localized in neuronal populations of the mammalian CNS together with NADPH diaphorase. Neuron, 7: 615-624.

9. Brüning G, Funk U \& Mayer B (1994). Immunocytochemical localization of nitric oxide synthase in the brain of the chicken. NeuroReport, 5: 2425-2428.

10. Brüning G, Katzbach R \& Mayer B (1995). Histochemical and immunocytochemical localization of nitric oxide synthase in the central nervous system of the goldfish, Carassius auratus. I. Journal of Comparative Neurology, 358: 353-382.

11. Brüning $G$ \& Mayer B (1996). Localization of nitric oxide synthase in the brain of the frog, Xenopus laevis. Brain Research, 741: 331-343.

12. Satoh $K$, Arai $R$, Ikemoto $M$, Narita $M$, Nagai $T$, Ohshima $H$ \& Kitahama K (1995). Distribution of nitric oxide synthase in the central nervous system of Macaca fuscata: subcortical regions. Neuroscience, 66: 685-696. 
13. Förstermann U, Boissel J \& Kleinert H (1998). Expressional control of the 'constitutive' isoforms of nitric oxide synthase (NOS I and NOS III). FASEB Journal, 12: 773-790.

14. Wu HH, Williams CV \& McLoo SC (1994). Involvement of nitric oxide in the elimination of transient retinotectal projection in development. Science, 265: 1593-1596.

15. Mize RR, Wu HH, Cork RJ \& Scheiner CA (1998). The role of nitric oxide in development of patch-cluster system and retinocollicular pathways in the rodent superior colliculus. Progress in Brain Research, 118: 134-152.

16. Campello-Costa P, Fosse Jr AM, Ribeiro JC, Paes-de-Carvalho R \& Serfaty CA (2000). Acute blockade of nitric oxide synthesis induces disorganization and amplifies lesion-induced plasticity in the rat retinotectal projection. Journal of Neurobiology, 44: 371-381.

17. Vercelli A, Garbossa D, Biasiol S, Repici M \& Jhaveri S (2000). NOS inhibition during postnatal development leads to increased ipsilateral retinocollicular and retinogeniculate projections in rats. European Journal of Neuroscience, 12: 473-490.

18. Wu HH, Cork RJ, Huang PL, Shuman DL \& Mize RR (2000). Refinement of the ipsilateral retinocollicular projections is disrupted in double endothelial and neuronal nitric oxide synthase gene knockout mice. Developmental Brain Research, 120: 105-111.

19. González-Hernández T, Conde-Sendín M, González-González B, Mantolan-Sarmiento B, Perez-González H \& Meyer G (1993). Postnatal development of NADPH-diaphorase activity in the superior colliculus and the ventral lateral geniculate nucleus of the rat. Developmental Brain Research, 76: 141-145.

20. Tenório F, Giraldi-Guimarães A \& Mendez-Otero R (1995). Developmental changes of nitric oxide synthase in the rat superior colliculus. Journal of Neuroscience Research, 42: 633-637.

21. Tenório F, Giraldi-Guimarães A \& Mendez-Otero R (1996). Morphology of NADPH-diaphorase-positive cells in the retinoceptive layers of the developing rat superior colliculus. International Journal of Developmental Neuroscience, 14: 1-10.

22. Giraldi-Guimarães A, Tenório F, Brüning G, Mayer B, Mendez-Otero $R$ \& Cavalcante LA (1999). Nitric oxide synthase expression in the opossum superior colliculus: a histochemical, immunohistochemical and biochemical study. Brain, Behavior and Evolution, 199: 303313.

23. Cork RJ, Calhouin T, Perrone M \& Mize RR (2000). Postnatal development of nitric oxide synthase expression in the mouse superior colliculus. Journal of Comparative Neurology, 427: 581-592.

24. Scheiner CA, Kratz KE, Guido W \& Mize RR (2001). Prenatal and postnatal expression of nitric oxide in the developing kitten superior colliculus revealed with NADPH diaphorase histochemistry. Visual Neuroscience, 18: 43-54

25. González-Soriano J, Contreras-Rodríguez J, Martínez-Sainz P, Martín-Palacios S, Marín-García P \& Rodríguez-Veiga E (2002). NADPH-diaphorase distribution in the rabbit superior colliculus and co-localization with calcium-binding proteins. Journal of Anatomy, 200: 297-308.
26. Langer TP \& Lund RD (1974). The upper layers of the superior colliculus: A Golgi study. Journal of Comparative Neurology, 158 : 405-436.

27. González-Hernández T, Conde-Sendín TM \& Meyer G (1992). Laminar distribution and morphology of NADPH-diaphorase containing neurons in the superior colliculus and underlying periaqueductal grey of the rat. Anatomy and Embryology, 186: 245-250.

28. Soares-Mota M, Henze I \& Mendez-Otero R (2001). Nitric oxide synthase-positive neurons in the rat superior colliculus: colocalization of NOS with NMDAR1 glutamate receptor, GABA and parvalbumin. Journal of Neuroscience Research, 64: 501-507.

29. Dinerman JL, Dawson TM, Schell MJ, Snowman A \& Snyder SH (1994). Endothelial nitric oxide synthase localized to hippocampal pyramidal cells: implications for synaptic plasticity. Proceedings of the National Academy of Sciences, USA, 91: 4214-4218.

30. Assreuy J, Cunha FQ, Liew FY \& Moncada S (1992). Feedback inhibition of nitric oxide synthase by nitric oxide. British Journal of Pharmacology, 108: 833-837.

31. Bradford MM (1976). A rapid and sensitive method for the quantitation of microgram quantities of protein utilizing the principle of protein-dye-binding. Analytical Biochemistry, 72: 248-254.

32. Batista C, Carneiro K, De Bittencourt-Navarrete RE, Soares-Mota M, Cavalcante LA \& Mendez-Otero R (2003). Nitrergic dendrites in the superficial layers of the rat superior colliculus: Retinal afferents and alternatively spliced isoforms in normal and deafferented animals. Journal of Neuroscience Research, 71: 455-461.

33. González-Hernandez T, Perez de la Cruz MA \& Mantolan-Sarmiento B (1996). Histochemical and immunohistochemical detection of neurons that produce nitric oxide: effect of different fixative parameters and immunoreactivity against non-neuronal NOS antisera. Journal of Histochemistry and Cytochemistry, 44: 1399-1413.

34. Daniel H, Hemart N, Jaillard T \& Crepel F (1993). Long-term depression requires nitric oxide and guanosine $3^{\prime}: 5^{\prime}$ cyclic monophosphate production in rat cerebellar Purkinje cells. European Journal of Neuroscience, 5: 1079-1082.

35. Son H, Hawkins RD, Martin K, Kiebler M, Huang PL, Fishman MC \& Kandel ER (1996). Long-term potentiation is reduced in mice that are doubly mutant in endothelial and neuronal nitric oxide synthase. Cell, 87: 1015-1023.

36. Holscher C (1997). Nitric oxide, the enigmatic neuronal messenger: its role in synaptic plasticity. Trends in Neurosciences, 20: 298-303.

37. Mize RR \& Lo FS (2000). Nitric oxide, impulse activity and neurotrophins in visual system development. Brain Research, 886: 15-32.

38. Prast $H$ \& Philippu A (2001). Nitric oxide as modulator of neuronal function. Progress in Neurobiology, 64: 51-68.

39. Simon DK \& O'Leary DD (1992). Development of topographic order in the mammalian retinocollicular projection. Journal of Neuroscience, 12: 1212-1232.

40. Lo FS \& Mize RR (2002). Properties of LTD and LTP of retinocollicular synaptic transmission in the developing rat superior colliculus. European Journal of Neuroscience, 15: 1421-1432. 